\title{
Pengolahan Tipikal Instalasi Pengolahan Air Limbah Industri Tahu di Kota Surabaya
}

\author{
Agung Wahyu Pamungkas dan Agus Slamet \\ Departemen Teknik Lingkungan, Fakultas Teknik Sipil dan Perencanaan, Institut Teknologi Sepuluh Nopember \\ (ITS) \\ e-mail: Suga@enviro.its.ac.id
}

\begin{abstract}
Abstrak-Industri tahu dalam proses produksinya menghasilkan limbah, baik limbah padat maupun cair dengan kadar BOD dan COD yang cukup tinggi. Kandungan bahan organik dalam limbah tahu, akan menurunkan daya dukung lingkungan apabila dibuang langsung ke lingkungan. Industri tahu sendiri umumnya adalah industri skala kecil yang membutuhkan pengolahan dengan investasi biaya serta O\&M yang terjangkau. Perencanaan bertujuan untuk merencanakan tipikal IPAL industri tahu di kota Surabaya. Tahapan perencanaan dimulai dari studi literatur, pengumpulan data, penelitian pendahuluan, pengolahan data, pembahasan dan kesimpulan. Data yang digunakan dalam perencanaan meliputi data primer berupa kualitas air limbah dan survey kondisi eksisting. Data sekunder berupa HSPK kota surabaya, data lokasi, dan data produksi. Data primer diambil dari kegiatan produksi tahu di 3 industri tahu berbeda di kota Surabaya. Data sekunder didapatkan dari dinas terkait dan industri yang bersangkutan. Perencanaan menggunakan rangkaian unit biodigester anaerobik dan 3 alternatif. Alternatif yang digunakan adalah unit Anaerobik Filter, Wetland, dan Aerobik Biofilter. Hasil evaluasi ditetapkan Anaerobik Filter sebagai model tipikal pabrik tahu terpilih. Pemilihan ini didasarkan pada efisiensi penurunan kualitas limbah dan penggunaan lahan. Pada industri dengan kapasitas produksi kecil digunakan unit digester dan unit Anaerobik Filter dengan 1 tangki filter. Biaya investasi yang dibutuhkan sebesar Rp. 200.571.373. Pada industri dengan kapasitas produksi menengah digunakan unit digester dan unit Anaerobik Filter dengan 3 tangki filter. Biaya investasi yang dibutuhkan sebesar Rp. 312.668.316. Pada industri dengan kapasitas produksi besar digunakan unit digester dan unit Anaerobik Filter dengan 6 tangki filter. Biaya investasi yang dibutuhkan sebesar Rp. 507.239.001.
\end{abstract}

Kata Kunci-Aerobik Biofilter, Anaerobik Filter, Biodigester Anaerobik, Limbah cair tahu, Wetland.

\section{PENDAHULUAN}

$\mathrm{P}$ ROSES produksi tahu di Indonesia umumnya masih dilakukan dengan teknologi sederhana. Hal tersebut berakibat pada tingkat efisiensi penggunaan sumber daya (air dan bahan baku) yang rendah dan tingkat produksi limbah yang tinggi. Kegiatan industri tahu di Indonesia didominasi oleh usaha-usaha skala kecil dengan modal yang terbatas. Dari segi lokasi, industri tahu tersebar di seluruh wilayah Indonesia. Sumber daya manusia yang terlibat dalam proses produksi tahu pada umumnya bertaraf pendidikan yang rendah.

Industri tahu dalam proses pengolahannya menghasilkan limbah baik limbah padat maupun cair. Limbah padat dihasilkan dari proses penyaringan dan penggumpalan. Limbah padat ini kebanyakan oleh pengrajin dijual dan diolah menjadi tempe gembus, kerupuk ampas tahu, pakan ternak, dan diolah menjadi tepung ampas tahu. Limbah cair dari produksi tahu dihasilkan dari proses pencucian, perebusan, pengepresan dan pencetakan tahu. Limbah cair yang dihasilkan memiliki kadar COD dan BOD yang tinggi, sehingga jika langsung dibuang ke badan air, akan menurunkan daya dukung lingkungan. Dengan demikian industri tahu memerlukan suatu pengolahan limbah yang bertujuan untuk mengurangi resiko beban pencemaran yang ada [1].

Air banyak digunakan sebagai bahan pencuci dan perebus kedelai, sehingga limbah yang dihasilkan juga cukup besar. Suhu air limbah tahu berkisar $37-45^{\circ} \mathrm{C}$, kekeruhan 535-585 FTU, warna 2.225-2.250 Pt.Co, amonia 23,3-23,5 mg/L, BOD5 6.000-8.000 mg/L dan COD 7.500-14.000 mg/L [2]. Menurut Peraturan Gubernur Jawa Timur no 52 tahun 2014 tentang Baku Mutu Limbah Cair bagi Kegiatan Industri, kadar maksimum yang diperbolehkan untuk BOD5, COD dan TSS berturut-turut sebesar 150,300 , dan $100 \mathrm{mg} / \mathrm{L}$, namun tidak dituliskan batas maksimal amonium dan nitrat. Dari pertimbangan tersebut, kita mengetahui bahwa limbah cair tahu ini telah melampaui baku mutu yang dipersyaratkan.

Pengolahan limbah cair industri tahu dapat dilakukan secara fisik-kimia maupun biologis. Secara fisik-kimia, teknologi atau alternatif pengolahan yang digunakan diantaranya adalah proses sedimentasi, dan koagulasi-flokulasi [3]. Proses biologi dapat berupa degradasi menggunakan bakteri secara aerob maupun anaerobik, dengan pertumbuhan bakteri terlekat maupun tersuspensi.

Dalam proses pemilihan alternatif pengolahan, perlu dipertimbangkan baik dari segi kemampuan dalam menyisihkan polutan, serta kemampuan finansial. Salah satu alternatif pengolahan yang banyak digunakan adalah proses degradasi anaerobik. Proses anaerobik memiliki kelebihan biaya operasi dan perawatan yang murah, lumpur yang terbentuk sedikit, serta memiliki efisiensi pengolahan zat organik yang tinggi. Disisi lain, removal nutrient dari proses anaerobik kecil, sehingga diperlukan proses lain untuk mengolah nutrien [4]. Teknologi pengolahan limbah tahu yang ada saat ini pada umumnya berupa pengolahan limbah dengan sistem anaerob. Proses pengolahan biologis secara anaerobik memiliki efisiensi pengolahan sekitar 70\%-80\% [2].

Limbah cair dengan kadar organik yang tinggi, diolah dengan unit yang memiliki efisiensi removal tinggi. Unit Biodigester Anaerobik mampu mengolah limbah cair dengan kadar organik yang tinggi. Unit ini mampu mereduksi COD hingga $80 \%$, N hingga 30\%, P hingga 55\%, serta Suspended solid hingga 50\% [5]. Unit lain seperti Anaerobik Filter (AF) mampu mereduksi COD hingga $86,9 \%$ dan $\mathrm{BOD}_{5}$ hingga $92,4 \%$ [6]. Unit Wetland mampu mengolah limbah cair yang 
memiliki kadar organik tinggi dengan removal COD mencapai $85 \%$, BOD $80 \%$, dan TSS hingga $46 \%$ [7]. Unit lain yang mampu mengolah limbah dengan kadar organik tinggi adalah Aerobik Biofilter. Unit Aerobik Biofilter mampu menurunkan BOD hingga $90 \%$ serta mereduksi phosporus, nitrogen, dan ammonia.

Industri tahu di surabaya akan dikelompokkan dalam 3 kategori berdasarkan kuantitas produksinya, yaitu kategori besar, sedang, dan kecil. Perencanaan ini akan berfokus pada analisa IPAL dengan unit Biodigester anaerobik dan salah satu dari 3 alternatif unit, yaitu Anaerobik Filter (AF), Wetland, atau Aerobik Biofilter. 3 alternatif tersebut dipilih karena mampu mengolah limbah cair dengan kadar organik tinggi. Penentuan alternatif yang digunakan di tiap kategorimya akan mengikuti kondisi di lapangan.

Perencanaan ini diharapkan mampu memberikan informasi mengenai model tipikal dalam pembangunan IPAL untuk industri tahu berdasarkan kategori yang ada. Adapun aspek yang dikaji adalah aspek teknis berkaitan dengan penentuan alternatif pengolahan limbah cair serta aspek finansial berkaitan dengan biaya investasi.

\section{METODE PERENCANAAN}

Perencanaan terdiri atas beberapa tahapan perencanaan. Tahapan perencanaan meliputi pelaksanaan studi literatur, pengumpulan data baik primer maupun sekunder, pelaksanaan perencanaan yang berupa perhitungan dan gambar, dan pembuatan laporan.

Perencanaan secara garis besar dibagi dalam 2 tahap. Tahap pertama merupakan tahap pengambilan data dimana data akan diambil dari 10 industri tahu di kota surabaya. Tahap pertama akan dikhususkan pada data sekunder, tujuannya adalah agar perencana mampu membuat dan menentukan 3 kategori industri tahu berdasarkan kapasitas produksinya. Selanjutnya diambil 1 industri tahu di tiap kategorinya guna dilakukan pengambilan data primer dan perencanaan lanjutan.

Tahap kedua merupakan tahap pengolahan data dan penulisan laporan. Pada tahap ini akan dibahas lebih rinci mengenai kualitas limbah, alternatif unit IPAL, DED IPAL industri tahu, serta biaya investasi. Perhitungan DED IPAL berbasis pada nilai HRT.

\section{HASIL DAN PEMBAHASAN}

\section{A. Industri Tahu di Surabaya}

Dinas Lingkungan Hidup kota Surabaya menyebutkan bahwa terdapat 10 industri tahu yang masih beroperasi di Surabaya. Daftar industri tahu di kota surabaya, beserta dengan produksi tahu harian dan pemakaian kedelai dapat dilihat pada tabel 1 berikut.

Industri tahu selanjutnya dikelompokkan menjadi 3 kelompok berdasarkan produksinya yaitu: besar, menengah, dan kecil. Kelompok besar adalah industri tahu dengan produksi harian diatas $500 \mathrm{~kg}$. Kelompok menengah adalah industri tahu dengan produksi harian antara 100-500 kg. Kelompok kecil adalah industri tahu dengan produksi harian dibawah $100 \mathrm{~kg}$. Dari tiap pengelompokan tersebut, penulis mengambil satu industri untuk di desain IPAL nya. Industri terpilih adalah kedung tarukan, tambang boyo dan kenjeran.
Kedung Tarukan mewakili industri tahu kategori besar, Tambang Boyo mewakili industri tahu dengan kategori menengah, dan kenjeran mewakili industri tahu dengan kategori kecil.

Tabel 1.

Data Industri Tahu

\begin{tabular}{clcc}
\hline \hline No & Industri tahu & Produksi (kg) & Pemakaian kedelai (kg) \\
& & & \\
\hline 1 & Sumber Kencono & 880 & 704 \\
2 & Saudara & 800 & 640 \\
3 & Kedungtarukan & 760 & 608 \\
4 & Bintang & 560 & 448 \\
5 & Halim & 340 & 272 \\
6 & Tambang Boyo & 320 & 256 \\
7 & Karang Asem & 240 & 192 \\
8 & Legowo & 200 & 160 \\
9 & Fusia & 60 & 48 \\
10 & Kenjeran & 40 & 32 \\
\hline \hline
\end{tabular}

Debit yang digunakan disesuaikan dengan literatur [8] dimana disebutkan bahwa dalam $1 \mathrm{~kg}$ bahan baku kedelai menghasilkan limbah cair sebanyak 15-20 L. debit limbah dari tiap industri ditunjukan dalam Tabel 2.

Tabel 2. Debit Limbah Produksi

\begin{tabular}{rlcc}
\hline \hline No & Industri Tahu & $\begin{array}{c}\text { Pemakaian Kedelai } \\
(\mathrm{kg})\end{array}$ & $\begin{array}{c}\text { Debit Limbah } \\
\text { Produksi (L) }\end{array}$ \\
\hline & Sumber & 704 & 10560 \\
1 & Kencono & 640 & 9600 \\
2 & Saudara & 608 & 9120 \\
3 & Kedungtarukan & 448 & 6720 \\
4 & Bintang & 272 & 4080 \\
5 & Halim & 256 & 3840 \\
6 & Tambang Boyo & 192 & 2880 \\
7 & Karang Asem & 160 & 2400 \\
8 & Legowo & 48 & 720 \\
9 & Fusia & 32 & 480 \\
10 & Kenjeran & & \\
\hline \hline
\end{tabular}

Parameter awal berupa kualitas air limbah produksi tahu dibutuhkan untuk merancang dimensi dari IPAL. Hasil uji laboratorium yang didapatkan penulis dari limbah ketiga pabrik tersebut dapat dilihat pada tabel 2 hingga tabel 4 mengenai kualitas air limbah.

Tabel 2 .

Kualitas Air Limbah Kategori Produksi Kecil

\begin{tabular}{ccc}
\hline \hline Parameter & Hasil Analisa & Satuan \\
\hline $\mathrm{pH}$ & 3,9 & $\mathrm{oC}$ \\
$\mathrm{TSS}$ & 1070 & $\mathrm{mg} / \mathrm{L}$ \\
$\mathrm{COD}$ & 4962 & $\mathrm{mg} / \mathrm{L}$ \\
BOD & 3026 & $\mathrm{mg} / \mathrm{L}$ \\
Nitrogen & 794,9 & $\mathrm{mg} / \mathrm{L}$ \\
Pospat & 116,12 & $\mathrm{mg} / \mathrm{L}$ \\
CO2 & 2150 & $\mathrm{mg} / \mathrm{L}$ \\
HCO3 & 1350 & $\mathrm{mg} / \mathrm{L}$ \\
\hline \hline
\end{tabular}

Apabila kita membanding kualitas limbah dari ketiga pabrik terpilih, terdapat perbedaan kualitas pada industri tahu kategori besar. Perbedaan beban sendiri kemungkinan besar terjadi karena adanya pengenceran. Pengambilan sampel pada 
pabrik kategori besar diambil terlalu siang, sebagian alat masak sudah dibereskan dan dibersihkan. Air yang digunakan untuk membersihkan bercampur dengan limbah tahu dalam saluran pembuangan, sehingga terjadi pengenceran. Tabel 3.

Kualitas Air Limbah Ketegori Produksi Menengah

\begin{tabular}{ccc}
\hline \hline Parameter & $\begin{array}{c}\text { Hasil } \\
\text { Analisa }\end{array}$ & Satuan \\
\hline $\mathrm{pH}$ & 4,6 & ${ }^{\circ} \mathrm{C}$ \\
$\mathrm{TSS}$ & 940 & $\mathrm{mg} / \mathrm{L}$ \\
$\mathrm{COD}$ & 5532 & $\mathrm{mg} / \mathrm{L}$ \\
$\mathrm{BOD}$ & 3374 & $\mathrm{mg} / \mathrm{L}$ \\
Nitrogen & 935,96 & $\mathrm{mg} / \mathrm{L}$ \\
Pospat & 231,87 & $\mathrm{mg} / \mathrm{L}$ \\
$\mathrm{CO} 2$ & 2250 & $\mathrm{mg} / \mathrm{L}$ \\
$\mathrm{HCO} 3$ & 450 & $\mathrm{mg} / \mathrm{L}$ \\
\hline \hline
\end{tabular}

Tabel 4. Kualitas Air Limbah Kategori Produksi Besar

\begin{tabular}{ccc}
\hline \hline Parameter & Hasil Analisa & Satuan \\
\hline $\mathrm{pH}$ & 4,65 & ${ }^{\circ} \mathrm{C}$ \\
$\mathrm{TSS}$ & 1340 & $\mathrm{mg} / \mathrm{L}$ \\
$\mathrm{COD}$ & 2912 & $\mathrm{mg} / \mathrm{L}$ \\
BOD & 1776 & $\mathrm{mg} / \mathrm{L}$ \\
Nitrogen & 353,87 & $\mathrm{mg} / \mathrm{L}$ \\
Pospat & 139,74 & $\mathrm{mg} / \mathrm{L}$ \\
$\mathrm{CO} 2$ & 1350 & $\mathrm{mg} / \mathrm{L}$ \\
$\mathrm{HCO} 3$ & 640 & $\mathrm{mg} / \mathrm{L}$ \\
\hline \hline
\end{tabular}

Effluent dari ketiga pabrik untuk parameter COD dan BOD disamakan menggunakan nilai tertinggi yang telah tercatat untuk menghindari perencanaan unit yang tidak sesuai, sehingga parameter ketiga pabrik adalah COD $5532 \mathrm{mg} / \mathrm{L}$ dan BOD 3374 mg/L.

\section{B. Perencanaan IPAL}

Setelah melalui tahap survey, penulis menemukan bahwa kondisi lahan yang memungkinkan untuk penempatan IPAL sangat terbatas. Ketersediaan lahan dapat dilihat pada tabel 5 berikut.

Tabel 5

Ketersediaan Lahan

\begin{tabular}{ccc}
\hline \hline Kenjeran & Tambang Boyo & Kedung Tarukan \\
\hline $88 \mathrm{~m}^{2}$ & $123 \mathrm{~m}^{2}$ & $176 \mathrm{~m}^{2}$ \\
\hline \hline
\end{tabular}

Keterbatasan lahan mempengaruhi pilihan alternatif yang bisa digunakan. Garis besar pengolahan limbah ditunjukkan pada gambar 1 dimana limbah tahu akan diolah dalam digester dan selanjutnya effluent dari digester bersama dengan grey water diolah dengan pengolahan lanjutan. Alternatif pengolahan terdiri dari Anaerobik Filter, wetland, dan Aerobik biofilter.

Berdasarkan Gambar 1, alternatif pertama menggunakan kombinasi Anaerobik Biodigester - Anaerobik Filter. Alternatif 2 menggunakan kombinasi Anaerobik Biodigester Wetland. Kombinasi 3 menggunakan kombinasi Anaerobik Biodigester - Aerobik Biofilter.

Anaerobik Biodigester digunakan untuk menurunkan kadar solid dan menghasilkan gas methan sebagai potensi energi. Alternatif antara Anaerobik Filter, Wetland, dan Aerobik
Filter dipilih karena penggunakan lahan yang relatif kecil dan efisiensi pengolahan yang tinggi.

Desain dari tiap unit selanjutnya dihitung. Pada contoh berikut, digunakan perhitungan unit dari industri tahu kategori menengah.

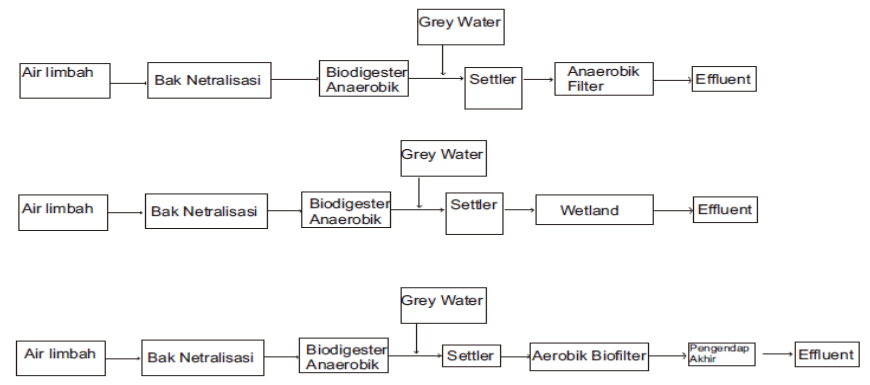

Gambar 1. Diagram Alir Proses Alternatif Pengolahan.

1. Desain Unit Anaerobik Biodigester

Kriteria disain yang umum digunakan untuk anaerobic digester low-rate dan high-rate [9] adalah sebagai berikut:

\begin{tabular}{|c|c|c|c|}
\hline Parameter & & Low rate & High rate \\
\hline Digestion Time, days & $=$ & $30-60$ & $10-20$ \\
\hline $\begin{array}{l}\text { Organic Solids Loading, } \\
\mathrm{kg} \text { vss } / \mathrm{m}^{3} \text {.day }\end{array}$ & $=$ & $0,64-1,60$ & $2,40-6,40$ \\
\hline depth $(\mathrm{m})$ & $=$ & $3,66-13,7$ & $3,66-13,7$ \\
\hline Diameter (m) & $=$ & $4,57-38,1$ & $4,57-38,1$ \\
\hline
\end{tabular}

Digester direncanakan menggunakan tipe fixed dome berbentuk lingkaran dan terdiri dari 2 unit

$$
\begin{array}{ll}
\mathrm{Q}=3840 \mathrm{~L} / \text { hari } & =3,84 \mathrm{~m}^{3} / \text { hari } \\
\text { HRT } & =30 \text { hari } \\
\text { Kedalaman air }(\mathrm{d}) & =4 \mathrm{~m} \\
\mathrm{D} & =4,30 \mathrm{~m}
\end{array}
$$

Desain dan ukuran unit digester untuk ketiga kategori industri dapat dilihat pada Gambar 2 dan Tabel 6.

Tabel 6.

Dimensi Anaerobik Digester

\begin{tabular}{lccc}
\hline \hline Kategori Industri & Diameter $(\mathrm{m})$ & Kedalaman $(\mathrm{m})$ & Jumlah Unit \\
\hline Kecil (a) & 2,15 & 4 & 1 \\
Menengah (b) & 4,30 & 4 & 2 \\
Besar (c) & 4,99 & 6 & 2 \\
\hline \hline
\end{tabular}

\section{Desain Anaerobik Filter}

Anaerobik Filter terdiri dari unit settler dan unit anaerobik filter itu sendiri. Anaerobic Filter (AF) memiliki kriteria desain sebagai berikut [10]:
Beban Organik
HRT di bak pengendap /
tangki septik
HRT di anaerobik Filter
BOD Removal
Rasio SS/BOD
Luas Spesifik Media
Velocity Upflow 


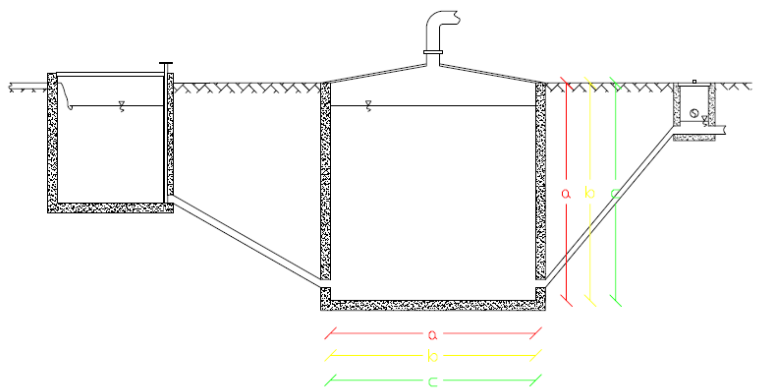

Gambar 2. Model Anaerobik Digester.

Settler terbagi atas dua ruang. Desain settler yang digunakan adalah sebagai berikut:
Waktu pengurasan $\quad=24$ bulan
Lebar dalam $\quad=3,5 \mathrm{~m}$
Kedalaman air $(\mathrm{d}) \quad=1,8 \mathrm{~m}$
Panjang ruang $1 \quad=1 \mathrm{~m}$
Panjang ruang $2=0,5 \mathrm{~m}$

Anaerobik Filter direncanakan menggunakan media sarang tawon yang memiliki luas permukaan spesifik tinggi. Desain Anaerobik Filter tiap tangkinya adalah sebagai berikut:
Kedalaman tangki (d) $=2,2 \mathrm{~m}$
Panjang filter $\quad=2,2 \mathrm{~m}$
Lebar filter $\quad=3,5 \mathrm{~m}$
Jarak filter ke muka air $=0,4 \mathrm{~m}$
Jarak filter ke dasar $\quad=0,6 \mathrm{~m}$
Tinggi penyangga $\quad=0,05 \mathrm{~m}$
Tinggi media $\quad=1,15 \mathrm{~m}$
Jumlah filter $\quad=3$ buah

Desain dan ukuran unit Anaerobik Filter untuk ketiga kategori industri dapat dilihat pada Gambar 3 dan Tabel 7 - 8 .

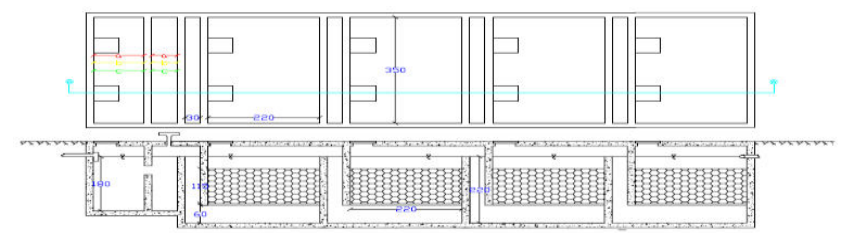

Gambar 3. Model Anaerobik Filter.

Tabel 7.

Dimensi Settler

\begin{tabular}{lcccc}
\hline \hline $\begin{array}{l}\text { Kategori } \\
\text { Industri }\end{array}$ & $\begin{array}{c}\text { Kedalaman } \\
(\mathrm{m})\end{array}$ & $\begin{array}{c}\text { Lebar } \\
(\mathrm{m})\end{array}$ & $\begin{array}{c}\text { Panjang ruang } \\
1(\mathrm{~m})\end{array}$ & $\begin{array}{c}\text { Panjang ruang } \\
2(\mathrm{~m})\end{array}$ \\
\hline Kecil (a) & 1,80 & 3,50 & 0,50 & 0,30 \\
Menengah & 1,80 & 3,50 & 1,00 & 0,50 \\
(b) & 1,80 & 3,50 & 1,50 & 1,00 \\
Besar (c) & P
\end{tabular}

Tabel 8.

Dimensi Anaerobik Filter

\begin{tabular}{lcccc}
\hline \hline $\begin{array}{c}\text { Kategori } \\
\text { Industri }\end{array}$ & $\begin{array}{c}\text { Jumlah } \\
\text { tangki }\end{array}$ & $\begin{array}{c}\text { kedalaman } \\
(\mathrm{m})\end{array}$ & $\begin{array}{c}\text { Lebar } \\
(\mathrm{m})\end{array}$ & $\begin{array}{c}\text { Panjang tangki } \\
(\mathrm{m})\end{array}$ \\
\hline Kecil (a) & 1 & 2,2 & 3,50 & 2,2 \\
Menengah & 3 & 2,2 & 3,50 & 2,2 \\
(b) & 6 & 2,2 & 3,50 & 2,2 \\
Besar (c) & 6 & & \\
\hline \hline
\end{tabular}

3. Desain Wetland

Wetland direncanakan menggunakan subsurface flow wetland. Wetland menggunakan tanaman Cattail (Typha Angustifolia) dan media gravel sand. Kriteria Desain Wetland
[11] ditunjukan pada Tabel 9. Desain wetland yang digunakan adalah sebagai berikut:

Tabel 9.

kriteria desain wetland

\begin{tabular}{lccc}
\hline \hline \multirow{2}{*}{ parameter desain } & \multirow{2}{*}{ Unit } & \multicolumn{2}{c}{ tipe sistem } \\
\cline { 3 - 4 } & & $\begin{array}{l}\text { Free Water } \\
\text { Surface }\end{array}$ & $\begin{array}{l}\text { Sub-surface flow } \\
\text { system }\end{array}$ \\
\hline Water Depth & $\mathrm{ft}$ & $0.3-2.0$ & $1.0-2.5$ \\
BOD Loading Rate & $\mathrm{b} / \mathrm{acre}$ & $<60$ & $<60$ \\
Hidraulic Loading & $\mathrm{Mgal} / \mathrm{acre} . \mathrm{d}$ & $0.015-0.050$ & $0.015-0.050$ \\
Rate & Acre/(Mgal/d) & $67-20$ & $67-20$ \\
Specific Area & & & \\
\hline \hline
\end{tabular}

$\begin{array}{ll}\text { Jarak Tanaman } & =15 \mathrm{~cm} \\ \text { Kedalaman media }(\mathrm{d}) & =0,6 \mathrm{~m} \\ \text { Slope (s) } & =0,01 \mathrm{~m} / \mathrm{m} \\ \text { Lebar(W) } & =1,72 \mathrm{~m} \\ \text { Panjang (L) } & =10 \mathrm{~m}\end{array}$

Desain dan ukuran unit wetland untuk ketiga kategori industri dapat dilihat pada Gambar 4 dan Tabel 10.

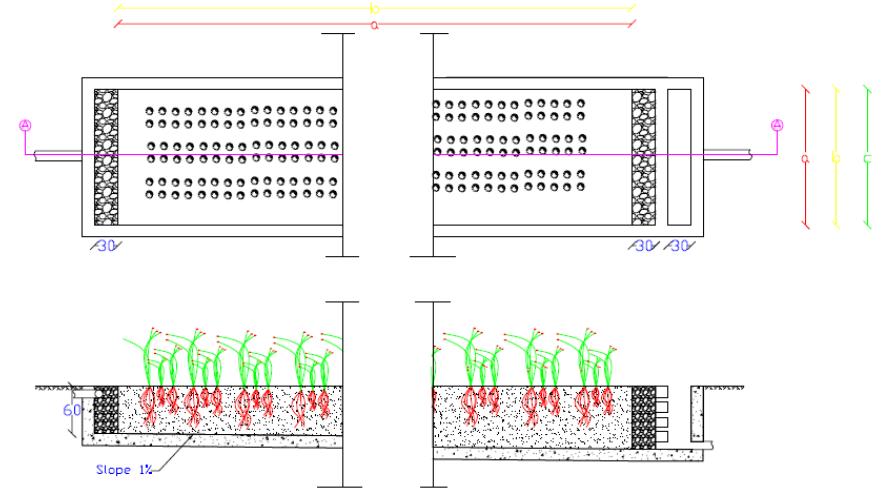

Gambar 4. Model Unit Wetland.

Tabel 10.

Dimensi Unit Wetland Hasil Perhitungan

\begin{tabular}{lcccc}
\hline \hline \multicolumn{1}{c}{$\begin{array}{c}\text { Kategori } \\
\text { Industri }\end{array}$} & $\begin{array}{c}\text { Panjang } \\
(\mathrm{m})\end{array}$ & Lebar $(\mathrm{m})$ & $\begin{array}{c}\text { Kedalaman } \\
(\mathrm{m})\end{array}$ & $\begin{array}{c}\text { Jumlah } \\
\text { Tanaman } \\
\text { (rumpun) }\end{array}$ \\
\hline Kecil (a) & 10 & 0,351759137 & 0,6 & 11 \\
$\begin{array}{l}\text { Menengah } \\
\text { (b) }\end{array}$ & 10 & 1,720933125 & 0,6 & 52 \\
Besar (c) & 10 & 4,03121515 & 0,6 & 121 \\
\hline \hline
\end{tabular}

4. Desain Aerobik Biofilter

Aerobik Biofilter terdiri dari 2 ruang, ruang aerasi dan ruang bed media. Unit ini membutuhkan unit pengendapan tambahan untuk mengendapkan biofilm yg terangkat dari bed media. Unit ini memiliki kriteria perencanaan sebagai berikut:
Organic Loading rate

$$
=<6 \mathrm{~kg} \mathrm{COD} / \mathrm{m}^{3} \text {.hari }
$$$$
\text { OLR BOD } \quad=0,3-2,0 \mathrm{~kg} \mathrm{BOD} / \mathrm{m}^{3} \text {.hari }
$$$$
\text { HRT di pengendap } \quad=\quad 2-4 \text { jam }
$$$$
\text { HRT di aerobik biofilter }=5-40 \text { jam }
$$

Desain dari unit Aerobik Biofilter adalah sebagai berikut:

$$
\text { Lebar } \quad=3,29 \mathrm{~m}
$$

Ruang Aerasi

$$
\begin{array}{ll}
\text { Kedalaman } & =2,2 \mathrm{~m} \\
\text { Panjang } & =1 \mathrm{~m}
\end{array}
$$

Ruang bed media

$$
\begin{array}{ll}
\text { Kedalaman } & =2,2 \mathrm{~m} \\
\text { Panjang } & =2 \mathrm{~m}
\end{array}
$$

Jarak filter ke muka air $=0,4 \mathrm{~m}$ 
Jarak filter ke dasar $\quad=0,6 \mathrm{~m}$

Tinggi penyangga $\quad=0,05 \mathrm{~m}$

Tinggi media $\quad=1,15 \mathrm{~m}$

Pengendap akhir

$\begin{array}{ll}\text { Lebar } & =3,29 \mathrm{~m} \\ \text { Kedalaman } & =2,2 \mathrm{~m} \\ \text { Panjang } & =1,8 \mathrm{~m}\end{array}$

Desain dan ukuran unit Aerobik Biofilter untuk ketiga kategori industri dapat dilihat pada Gambar 5 dan Tabel 11.
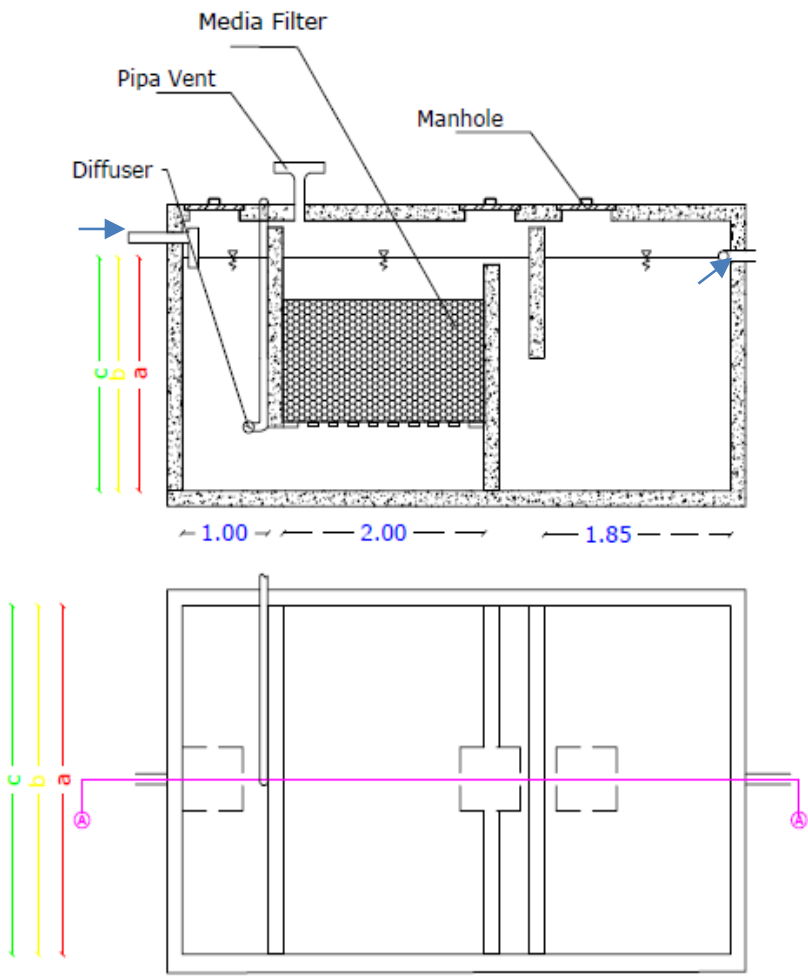

Gambar 5. Model Aerobik Biofilter

Tabel 11.

Dimensi Aerobik Biofilter

\begin{tabular}{lccc}
\hline \hline \multirow{2}{*}{ Kategori Industri } & $\begin{array}{c}\text { Lebar } \\
(\mathrm{m})\end{array}$ & $\begin{array}{c}\text { Redalaman aerasi } \\
\text { Km })\end{array}$ & $\begin{array}{c}\text { Panjang } \\
(\mathrm{m})\end{array}$ \\
\hline Kecil (a) & 0,98 & 1,5 & 1 \\
Menengah (b) & 3,29 & 2,2 & 1 \\
Besar (c) & 3,85 & 2,2 & 1 \\
& \multicolumn{3}{c}{ Ruang Bed Media } \\
\cline { 2 - 4 } Kategori Industri & $\begin{array}{c}\text { Lebar } \\
\text { (m) }\end{array}$ & $\begin{array}{c}\text { Kedalaman } \\
\text { (m) }\end{array}$ & $\begin{array}{c}\text { Panjang } \\
(\mathrm{m})\end{array}$ \\
\hline Kecil (a) & 0,98 & 1,5 & 2 \\
Menengah (b) & 3,29 & 2,2 & 2 \\
Besar (c) & 3,85 & 2,2 & 2 \\
\hline \multirow{3}{*}{ Kategori Industri } & \multicolumn{3}{c}{ Pengendap Akhir } \\
& $(\mathrm{m})$ & Kedalaman & Panjang \\
Kecil (a) & 0,98 & 1,5 & $(\mathrm{~m})$ \\
Menengah (b) & 3,29 & 2,2 & 1,8 \\
Besar (c) & 3,85 & 2,2 & 1,8 \\
\hline \hline
\end{tabular}

5. Effluent dan Penggunaan Lahan

Effluen dari IPAL selanjutnya dibuang ke badan air. Kualitas effluent serta penggunaan lahan dari ketiga alternatif pada ketiga kategori industri dapat dilihat pada tabel 12. Baku mutu yang digunakan mengacu pada Pergub Jatim no 72 th 2013.
Sistem Ipal yang digunakan untuk ketiga pabrik adalah alternatif pertama, kombinasi Anaerobik BiodigesterAnaerobik Filter, karena kemampuannya dalam mereduksi limbah dan penggunaan lahan yang mencukupi.

\section{Biaya Investasi}

Biaya investasi dihitung berdasarkan HSPK perubahan III 2016 kota Surabaya. Biaya investasi yang diperlukan untuk konstruksi IPAL pada ketiga kategori industri dapat dilihat pada Tabel 13.

Tabel 12.

Kualitas Effluent dan Kebutuhan Lahan

\begin{tabular}{clcccc}
\hline \hline Alternatif & \multicolumn{1}{c}{ Parameter } & $\mathrm{A}$ & $\mathrm{b}$ & $\mathrm{c}$ & $\begin{array}{c}\text { Baku Mutu } \\
(\mathrm{mg} / \mathrm{L})\end{array}$ \\
\hline \multirow{4}{*}{ I } & $\begin{array}{l}\text { BOD eff } \\
(\mathrm{mg} / \mathrm{L})\end{array}$ & 109 & 116 & 8 & 150 \\
& $\begin{array}{l}\text { COD eff } \\
(\mathrm{mg} / \mathrm{L})\end{array}$ & 282,71 & 234,27 & 58,25 & 300 \\
& $\begin{array}{l}\text { TSS eff } \\
(\mathrm{mg} / \mathrm{L})\end{array}$ & 46,32 & 49,94 & 72,18 & 100 \\
& Lahan $\left(\mathrm{m}^{2}\right)$ & 14,64 & 60,09 & 99,02 & \\
\hline \multirow{6}{*}{ II } & $\begin{array}{l}\text { BOD eff } \\
(\mathrm{mg} / \mathrm{L})\end{array}$ & 150 & 150 & 150 & 150 \\
& $\begin{array}{l}\text { COD eff } \\
(\mathrm{mg} / \mathrm{L})\end{array}$ & 274,09 & 414,20 & 419,96 & 300 \\
& $\begin{array}{l}\text { TSS eff } \\
(\mathrm{mg} / \mathrm{L})\end{array}$ & 77,20 & 83,23 & 120,30 & 100 \\
& Lahan $\left(\mathrm{m}^{2}\right)$ & 10,46 & 54,20 & 93,13 & \\
\hline \multirow{3}{*}{ III } & $\begin{array}{l}\text { BOD eff } \\
(\mathrm{mg} / \mathrm{L})\end{array}$ & 395 & 597 & 606 & 150 \\
& $\begin{array}{l}\text { COD eff } \\
(\mathrm{mg} / \mathrm{L})\end{array}$ & 798,98 & 1207,44 & 1224,21 & 300 \\
& $\begin{array}{l}\text { TSS eff } \\
(\mathrm{mg} / \mathrm{L})\end{array}$ & 106,15 & 114,45 & 165,41 & 100 \\
& Lahan (m $\left.{ }^{2}\right)$ & 9,38 & 46,43 & 60,89 & \\
\hline
\end{tabular}

Tabel 13

Biaya Investasi

\begin{tabular}{lc}
\hline \hline \multicolumn{1}{c}{ Industri } & Investasi \\
\hline Kecil & Rp 200.571.373 \\
Menengah & Rp 312.668 .316 \\
Besar & Rp 507.239.001 \\
\hline \hline
\end{tabular}

\section{KESIMPULAN}

Hasil dari perencanaan ini adalah:

1. Digunakan alternatif pertama, yaitu kombinasi Anaerobik Biodigester-Anaerobik Filter untuk ke tiga industri tahu. Pemilihan ini didasarkan pada efisiensi penurunan kualitas limbah dan penggunaan lahan. Industri dengan kategori produksi kecil, digunakan IPAL berupa 1 unit Biodigester dilanjutkan dengan 1 unit Settler-Anaerobik Filter. Anaerobik filter terdiri dari 1 tangki filter. Biaya investasi pembangunan yang dibutuhkan adalah Rp 200.571.373. Industri dengan kategori produksi menengah, digunakan IPAL berupa 2 unit Biodigester dilanjutkan dengan 1 unit Settler-Anaerobik Filter. Anaerobik filter terdiri dari 3 tangki filter. Biaya investasi pembangunan yang dibutuhkan adalah $\mathrm{Rp}$ 312.668.316. Industri dengan kategori produksi besar, digunakan IPAL berupa 2 unit Biodigester dilanjutkan dengan 1-unit Settler-Anaerobik Filter. Anaerobik filter terdiri dari 6 tangki filter. Biaya investasi pembangunan yang dibutuhkan adalah $\mathrm{Rp}$ 507.239 .001 


\section{DAFTAR PUSTAKA}

[1] F. Kaswinarni, "Kajian Teknis Pengolahan Limbah Padat dan Cair Industri Tahu Studi Kasus Industri Tahu Tandang Semarang, Sederhana Kendal dan Gagak Sipat Boyolali," Universitas Diponegoro, 2007.

[2] Herlambang, "Teknologi Pengolahan Limbah Cair Industri Tahu," Jakarta, 2002.

[3] D. Pokhrel and T. Viraraghavan, "Treatment of pulp and paper mill wastewater - a review," Sci. Tot. Env, vol. 333, pp. 37-58, 2004.

[4] A. Tarek and et al, "Biodegradibility and Change of Physical Characteristics of Particles During Anaerobic Digestion of Domestic Sewage," Wat. Res, vol. 35, no. 5, pp. 1311-1317, 2001.

[5] K. W. Endah, "Perencanaan Biodigester Tinja Manusia dan Kotoran Ternak Skala Komunal Rumah Tangga di Kecamatan Ngancar, Kabupaten Kediri," Institut Teknologi Sepuluh Nopember, 2012.
[6] D. Prakoso, "Desain Ioal Komunal Limbah Domestik Perumahan Sukolilo Dian Regency Dengan Teknologi Constructed Wetland," Institut Teknologi Sepuluh Nopember, 2016.

[7] E. Tilley, L. Ulrich, C. Lüthi, P. Reymond, and C. Zurbrügg, Compendium of Sanitation Systems and Technologies 2nd revised edition. Dübendorf: EAWAG.

[8] M. Soepardi and C. Potter, "Limbah Cair Berbagai Industri di Indonesia Serta Sumber Pengendalian Dan Baku Mutu,” 2000.

[9] Reynold, Unit Operations and Processes in Environtmental Engineering. PWS Publishing Company, 1996.

[10] L. Sasse, DEWATS. Decentralized Wastewater Treatment in Developing Countries. Bremen: Borda, 2009.

[11] Metcalf and Eddy, Wastewater Engineering Treatment Disposal Reuse, 5th ed. Mc Graw Hill, 2014. 